\title{
Informing Science Special Issue on Information Science Research
}

\author{
Amanda Spink \\ The Pennsylvania State University \\ Editor of this Special Issue on Information Science Research \\ spink@ist.psu.edu
}

\section{Introduction}

The papers in this Special Issue of Informing Science highlight research areas in the interdisciplinary field of Information Science. Key research problems for Information Science include: (1) how to model and effectively support human information behaviors, including information seeking and use behaviors, and interaction with information retrieval (IR) technologies, (2) how information should be organized intellectually in IR technologies for more effective human information retrieval, and (3) the organizational, social and policy implications for the information society of human information behaviors. Information Scientists are concerned with how people's information problems can be resolved. In this way, information science is an important part of the "informing sciences". Information Science has largely borrowed theories and approaches from other disciplines - but is now attracting attention from other disciplines as a generator of theory and models that delineate key areas of human information-related endeavors. As humans struggle to seek and use information within the plethora of information sources increasingly available via the Web, Information Science research is taking center stage. Each paper in this special issue is written by an expert in their area of Information Science research.

Apart from Tom Wilson, who has a long history in his research area, the authors are relatively young researchers in their field who are carving out significant research areas and making important contributions to the development of the field of information science.

The first paper on Human Information Behavior was written by Tom Wilson from the University of Sheffield, who is a pioneer in this growing research area. His paper provides a

Material published as part of this journal, either on-line or in print, is copyrighted by the publisher of Informing Science. Permission to make digital or paper copy of part or all of these works for personal or classroom use is granted without fee provided that the copies are not made or distributed for profit or commercial advantage AND that copies 1) bear this notice in full and 2) give the full citation on the first page. It is permissible to abstract these works so long as credit is given. To copy in all other cases or to republish or to post on a server or to redistribute to lists requires specific permission and payment of a fee. Contact Editor@inform.nu to request redistribution permission. good introduction to the research that seeks to model human information behaviors.

The second paper on Interactive Information Retrieval by David Robins from Louisiana State University, discusses research that models human interactions with IR systems. David highlights the exciting research areas surrounding human interaction with IR technologies.

The third paper on Image Retrieval by Abby Goodrum from Drexel University, details image retrieval studies. Abby describes this important area of information science research central to the human search for images.

The fourth paper on Relevance was written by Howard Greisdorf from the University of North Texas, who has conducted many studies focusing on the nature of human relevance judgments. Howard discusses the latest relevance research with implications for how we design IT technologies.

The fifth paper on Web Retrieval is by Amanda Spink of The Pennsylvania State University. Amanda discusses findings from a major study of Web searching by Excite users.

The sixth paper on Informetrics is by Dietmar Wolfram from the University of Wisconsin-Madison, whose work focuses on the quantitative study of regularities in information processes. Dietmar provides a good introduction to the informetric properties of IR systems.

The seventh paper on Organization of Information is by Jian Qin from Syracuse University whose work is key to issues related to the classification of the Web. Jian takes us through the issues associated with organizing the Web information space.

Our final paper on Social Informatics is by Steve Sawyer from Penn State and Howard Rosenbaum from Indiana University who conduct research in the social and organizational aspects of information technology design and use. Social informatics is key to understanding the relationships between information systems and people. 